\title{
Factors Associated with Decreased Lean Tissue Index in Patients with Chronic Kidney Disease
}

\author{
Yi-Wen Wang ${ }^{1,+}$, Ting-Yun Lin ${ }^{2,+}$, Ching-Hsiu Peng ${ }^{2}$, Jui-Lin Huang ${ }^{2}$ and Szu-Chun Hung ${ }^{2, *}$ \\ 1 Division of Family Medicine, Taipei Tzu Chi Hospital, Buddhist Tzu Chi Medical Foundation, \\ and School of Medicine, Tzu Chi University, Hualien 970, Taiwan; tk7643@hotmail.com \\ 2 Division of Nephrology, Taipei Tzu Chi Hospital, Buddhist Tzu Chi Medical Foundation, \\ and School of Medicine, Tzu Chi University, Hualien 970, Taiwan; water_h2o_6@hotmail.com (T.-Y.L.); \\ soranos2008@yahoo.com.tw (C.-H.P.); Lancelot_Lien@tw.tdk.com (J.-L.H.) \\ * Correspondence: szuchun.hung@gmail.com; Tel.: +886-2-6628-9779; Fax: +886-2-6629-2206 \\ + These authors contributed equally to this work.
}

Received: 24 February 2017; Accepted: 25 April 2017; Published: 27 April 2017

\begin{abstract}
Muscle wasting is common and is associated with increased morbidity and mortality in patients with chronic kidney disease (CKD). However, factors associated with decreased muscle mass in CKD patients are seldom reported. We performed a cross-sectional study of 326 patients (age $65.8 \pm 13.3$ years) with stage 3-5 CKD who were not yet on dialysis. Muscle mass was determined using the Body Composition Monitor (BCM), a multifrequency bioimpedance spectroscopy device, and was expressed as the lean tissue index (LTI, lean tissue mass $/$ height $^{2}$ ). An LTI of less than $10 \%$ of the normal value (low LTI) indicates muscle wasting. Patients with low LTI $(n=40)$ tended to be diabetic, had significantly higher fat tissue index, urine protein creatinine ratio, and interleukin- 6 and tumor necrosis factor- $\alpha$ levels, but had significantly lower serum albumin and hemoglobin levels compared with those with normal LTI. In multivariate linear regression analysis, age, sex, cardiovascular disease, and interleukin-6 were independently associated with LTI. Additionally, diabetes mellitus remained an independent predictor of muscle wasting according to low LTI by multivariate logistic regression analysis. We conclude that LTI has important clinical correlations. Determination of LTI may aid in clinical assessment by helping to identify muscle wasting among patients with stage 3-5 CKD.
\end{abstract}

Keywords: bioimpedance; body composition; cardiovascular disease; chronic kidney disease; inflammation; lean tissue index; muscle mass; protein energy wasting

\section{Introduction}

Body composition is one of the best indicators of overall health. Muscle wasting is common and progressive in patients with chronic kidney disease (CKD) and has important health consequences $[1,2]$. The term "sarcopenia", as defined by the European Working Group on Sarcopenia in Older People (EWGSOP), describes the presence of both low muscle mass and low muscle function (strength or performance) [3]. Recent studies have reported that the prevalence of sarcopenia or muscle wasting among patients with end-stage renal disease (ESRD) on dialysis ranges from $20 \%$ to $44 \%$ [4-7], which is significantly higher than in the healthy population.

In adults without $C K D$, a loss of muscle mass of $1 \%$ per year is expected $[8,9]$. However, in patients with CKD, loss of muscle mass occurs earlier and is much more rapid [10]. Sarcopenia or reduced muscle mass is associated with osteoporosis [11], a higher risk of fracture [12], physical disability [13], functional impairment, hospitalization, increased health costs, and higher mortality in the general population [14-17]. Recently, it has been shown that muscle wasting is associated with a higher risk of mortality in hemodialysis (HD) patients [5]. Identification and treatment of the underlying cause are 
required. However, factors associated with decreased muscle mass in non-dialysis CKD patients are seldom reported.

In order to improve the prognosis of CKD patients, sarcopenia should be screened for and detected during mild to moderate stages of $C K D$, when the complications of reduced muscle mass may be reversible [18]. Bioimpedance spectroscopy is a simple and effective approach for the assessment of body composition. The Body Composition Monitor (BCM, Fresenius Medical Care, Bad Homburg, Germany) is a bedside whole-body bioimpedance spectroscopy device for clinical use. The accuracy of body composition measurements has been validated against available gold standard reference methods including dual energy X-ray absorptiometry (DEXA) $[19,20]$. Moreover, the safe and accurate use of the BCM has been ensured in CKD patients with and without dialysis [21-23]. Therefore, the aim of this study was to determine muscle mass using the BCM device and to identify factors associated with decreased muscle mass in non-dialysis CKD patients.

\section{Materials and Methods}

\subsection{Design and Participants}

This was a cross-sectional study conducted in the Taipei Tzu Chi Hospital, Taiwan. This study complied with the Declaration of Helsinki and was approved by the Institutional Review Board (01-XD13-034). All participants gave written informed consent. Patients with prevalent stage 3-5 CKD who had been seen in outpatient clinics but who were not yet on dialysis were assessed for eligibility for inclusion if they were $>18$ years of age. CKD was defined on the basis of two (separated by an interval of $>3$ months) estimated glomerular filtration rate (eGFR) values $<60 \mathrm{~mL} / \mathrm{min}$ per $1.73 \mathrm{~m}^{2}$, as calculated by a simplified Modifications of Diet in Renal Disease (MDRD) equation. All patients received multidisciplinary CKD care, focusing on dietary salt and protein restriction, nephrotoxin avoidance, and strict blood pressure and glycemic control. Patients were excluded if they had a cardiac pacemaker or metallic implants, or were amputees. Patients were also excluded if they had malignancies or clinical conditions affecting body composition, such as liver cirrhosis, active inflammatory diseases, or any acute cardiovascular event during the three months before screening for inclusion.

For each patient, a medical history was taken at the time of enrollment. Diabetes mellitus (DM) was defined as the current or past use of insulin and/or oral antidiabetic drugs. Hypertension was defined by a blood pressure $\geq 140 / 90 \mathrm{~mm} \mathrm{Hg}$ or by receiving treatment with anti-hypertensive agents. The definition of cardiovascular disease (CVD) included coronary artery disease, as documented by coronary angiography or a history of myocardial infarction, class III to IV congestive heart failure, or cerebrovascular accidents. Smoking history was defined as any use of tobacco.

\subsection{Laboratory Measurements}

Plasma levels of interleukin-6 (IL-6), tumor necrosis factor $\alpha$ (TNF- $\alpha$ ) (R\&D Systems, Minneapolis, MN, USA), and N-terminal pro-brain natriuretic peptide (NT-proBNP; Roche Diagnostics, Indianapolis, IN, USA) were determined using commercially available enzyme-linked immunosorbent assay kits according to the manufacturers' instructions. Serum albumin levels were measured using a bromocresol purple (BCP) assay. Proteinuria was determined based on the urine protein-to-creatinine ratio (UPCR) assessed using the first morning void. Arterial stiffness was obtained by measuring the brachial-ankle pulse wave velocity (baPWV) using a VP-1000 analyzer (Colin Corporation, Komaki, Japan).

\subsection{Body Composition Measurements}

Body composition was assessed using the BCM device. Electrodes were placed on the hand and foot on the nondominant side of the body while the patient was in a supine position, and the results were available within $2 \mathrm{~min}$. The BCM measures body composition by analyzing electrical responses at 50 different frequencies between 5 and $1000 \mathrm{kHz}$. The use of multiple frequencies enables the calculation of theoretical resistance values at zero and infinite frequencies by fitting a polynomial 
curve termed the Cole-Cole plot. The validity of the measurement can be assessed by the graphic representation of the curve. Only patients with at least one valid BCM measurement were included in the study.

Input parameters included the patient's age, sex, height, and weight. Muscle mass was expressed as the lean tissue mass or lean tissue index (LTI, lean tissue mass $/$ height $^{2}$ ), which was derived from the impedance data based on a three-compartment model (lean tissue mass, adipose tissue mass, and overhydration) [23]. The BCM can distinguish muscle mass from pathologic fluid retention (overhydration). As a result, the sum of lean tissue mass and adipose tissue mass equals the body weight when no excess fluid is present in the body. According to the measured LTI compared with the age- and gender-normalized LTI value, patients with an LTI less than $10 \%$ of the normal value were considered to have muscle wasting [5,24]. Patients with an LTI of $10 \%$ or greater were considered to have a normal LTI. The BCM device has been validated in a study involving 500 healthy people with the same ethnic background in our study (Taiwanese). Almost all output parameters fit into the same reference ranges set by the Fresenius Medical Care, Bad Homburg, Germany [22,23].

\subsection{Statistical Analysis}

All of the variables were reported as the frequency and percentage for categorical data and as the mean \pm SD or median and interquartile range for continuous data with or without a normal distribution, respectively. The study population was further divided into two subgroups according to low (less than $10 \%$ of the normal value) or normal LTI. For all comparisons of baseline characteristics between the two subgroups, Student's $t$-test or the Mann-Whitney $U$-test was used to compare continuous variables. Categorical variables were compared by using a $\chi^{2}$ test. Univariate correlations between LTI and potential explanatory variables were assessed by Pearson's correlation coefficient. Multivariate linear and logistic regression analyses were conducted with the LTI and the presence of muscle wasting (defined as LTI $<10 \%$ of the normal value) as dependent variables and potential predictors (Age, sex, DM, CVD, eGFR, and log IL-6) as independent variables. A two-tailed $p$-value $<0.05$ was considered statistically significant. Statistical analysis was performed using the computer software Statistical Package for the Social Sciences, version 20 (SPSS, IBM, Armonk, NY, USA).

\section{Results}

\subsection{Population Characteristics}

After the exclusion criteria were applied, 338 clinically stable patients were enrolled in the study. Twelve patients were excluded from the analysis due to loss of follow-up after the initial visit $(n=8)$ or the initiation of chronic dialysis within the first month after enrollment $(n=4)$. The baseline characteristics of the remaining 326 patients, divided according to low or normal LTI, are presented in Table 1. Overall, $45.4 \%(n=148)$ of the study population had DM and $23.6 \%(n=77)$ had pre-existing CVD. All patients had moderate to severe CKD (mean eGFR $28.8 \pm 14.7 \mathrm{~mL} / \mathrm{min}$ per $1.73 \mathrm{~m}^{2} ; n=146$ in stage 3; $n=107$ in stage 4 ; and $n=73$ in stage 5). Patients in the low LTI group were more likely to have DM and a smoking history. Furthermore, patients with a low LTI had significantly higher levels of fat tissue index, UPCR, IL-6, and TNF- $\alpha$ but had significantly lower levels of serum albumin and hemoglobin. 
Table 1. Characteristics of CKD patients categorized according to low or normal LTI. Abbreviations: baPWV, brachial-ankle pulse wave velocity; BP, blood pressure; CKD, chronic kidney disease; CVD, cardiovascular disease; DM, diabetes mellitus; eGFR, estimated glomerular filtration rate; hs-CRP, high-sensitivity C-reactive protein; IL-6, interleukin-6; LTI, lean tissue index; RAS, renin-angiotensin system; TNF- $\alpha$, tumor necrosis factor $\alpha$; UPCR, urine protein creatinine ratio.

\begin{tabular}{cccc}
\hline \multirow{2}{*}{ Characteristic } & \multicolumn{2}{c}{ LTI $\left(\mathbf{k g} / \mathbf{m}^{\mathbf{2}}\right)$} & \multirow{2}{*}{$\boldsymbol{p}$ Value } \\
\cline { 2 - 3 } & $<\mathbf{1 0} \%(\boldsymbol{n = 4 0 )}$ & $\mathbf{1 0 \%}(\mathbf{n = 2 8 6 )}$ & \\
\hline Age (years) & $63.9 \pm 11.8$ & $66.1 \pm 13.5$ & 0.331 \\
Male sex, $n(\%)$ & $26(63.4 \%)$ & $198(69.5 \%)$ & 0.434 \\
Smoking history, $n(\%)$ & $14(34.1 \%)$ & $53(18.6 \%)$ & 0.021 \\
DM, $n(\%)$ & $26(63.4 \%)$ & $122(42.8 \%)$ & 0.013 \\
CVD, $n(\%)$ & $11(26.8 \%)$ & $66(23.2 \%)$ & 0.605 \\
Systolic BP $(\mathrm{mmHg})$ & $139.2 \pm 16.4$ & $137.4 \pm 17.3$ & 0.530 \\
baPWV $(\mathrm{m} / \mathrm{s})$ & $16.5 \pm 2.8$ & $15.9 \pm 3.1$ & 0.262 \\
RAS blockers, $n(\%)$ & $20(48.8 \%)$ & $176(61.8 \%)$ & 0.113 \\
Statin, $n(\%)$ & $15(36.6 \%)$ & $71(24.9 \%)$ & 0.113 \\
Body mass index $\left(\mathrm{kg} / \mathrm{m}^{2}\right)$ & $24.8 \pm 4.9$ & $26.0 \pm 4.0$ & 0.081 \\
Fat tissue index $\left(\mathrm{kg} / \mathrm{m}^{2}\right)$ & $12.1 \pm 5.1$ & $9.4 \pm 4.1$ & 0.000 \\
eGFR $\left(\mathrm{mL} / \mathrm{min} / 1.73 \mathrm{~m}{ }^{2}\right)$ & $25.3 \pm 14.6$ & $29.4 \pm 14.7$ & 0.098 \\
UPCR $(\mathrm{g} / \mathrm{g})$ & $1.40(0.55-4.21)$ & $0.81(0.30-2.22)$ & 0.020 \\
Albumin $(\mathrm{g} / \mathrm{dL})$ & $3.4 \pm 0.4$ & $3.6 \pm 0.4$ & 0.007 \\
Fasting glucose $(\mathrm{mg} / \mathrm{dL})$ & $122 \pm 40$ & $121 \pm 42$ & 0.816 \\
Total cholesterol $(\mathrm{mg} / \mathrm{dL})$ & $173 \pm 45$ & $175 \pm 40$ & 0.791 \\
Triglyceride $(\mathrm{mg} / \mathrm{dL})$ & $163 \pm 80$ & $164 \pm 119$ & 0.958 \\
hs-CRP $(\mathrm{mg} / \mathrm{L})$ & $3.8(1.5-10.8)$ & $3.9(1.3-9.6)$ & 0.910 \\
IL-6 $(\mathrm{pg} / \mathrm{mL})$ & $5.86(2.82-8.86)$ & $3.42(2.04-5.41)$ & 0.017 \\
TNF- $\alpha(\mathrm{pg} / \mathrm{mL})$ & $8.25(5.79-11.23)$ & $6.45(4.47-9.15)$ & 0.002 \\
Hemoglobin $(\mathrm{g} / \mathrm{dL})$ & $11.0 \pm 1.9$ & $12.0 \pm 2.1$ & 0.011 \\
\hline
\end{tabular}

\subsection{Factors Associated with LTI}

In univariate analysis, LTI was positively associated with body mass index $(r=0.284, p<0.001)$ and negatively associated with fat tissue index $(r=-0.432, p<0.001)$. Correlations between LTI and other variables are presented in Figure 1A-D. LTI was positively correlated with serum albumin $(r=0.197, p<0.001)$ (Figure 1A) and eGFR $(r=0.267, p<0.001)$ (Figure 1B), and negatively correlated with age $(r=-0.415, p<0.001)$ (Figure 1C) and log IL-6 $(r=-0.248, p<0.001)$ (Figure 1D).

Results of the multivariate linear and logistic regression analyses are presented in Tables 2 and 3. Stepwise multivariate linear regression analysis showed that age, sex, CVD, and log IL-6 were independently associated with LTI (adjusted $R^{2}$ of the model $=0.454$ ) (Table 2). In logistic regression analysis, DM remained an independent predictor of the presence of muscle wasting according to low LTI (Table 3).

Table 2. Stepwise multivariate linear regression model identifying determinants of LTI. Abbreviations: CVD, cardiovascular disease; IL-6, interleukin-6; LTI, lean tissue index.

\begin{tabular}{ccccc}
\hline Variable & Standard Error & Beta Coefficient & $\boldsymbol{t}$ & $\boldsymbol{p}$ Value \\
\hline Age & 0.010 & -0.358 & -8.360 & 0.000 \\
Male sex & 0.285 & 0.505 & 12.225 & 0.000 \\
CVD & 0.318 & -0.085 & -2.008 & 0.045 \\
$\log \mathrm{IL}-6(\mathrm{pg} / \mathrm{mL})$ & 0.355 & -0.104 & -2.401 & 0.017 \\
\hline
\end{tabular}


Table 3. Multivariate logistic regression model for patients with low LTI $(<10 \%$ of the normal value). Abbreviations: $\mathrm{CI}$, confidence interval; CVD, cardiovascular disease; $\mathrm{DM}$, diabetes mellitus; eGFR, estimated glomerular filtration rate; IL-6, interleukin-6; LTI, lean tissue index; OR, odds ratio.

\begin{tabular}{cccc}
\hline Variable & OR & $\mathbf{9 5 \%}$ CI & $p$ Value \\
\hline Age & 0.979 & 0.954 to 1.006 & 0.125 \\
Male sex & 0.969 & 0.469 to 2.005 & 0.933 \\
DM & 2.058 & 1.002 to 4.226 & 0.049 \\
CVD & 0.909 & 0.410 to 2.017 & 0.815 \\
eGFR $\left(\mathrm{mL} / \mathrm{min} / 1.73 \mathrm{~m}^{2}\right)$ & 0.981 & 0.957 to 1.006 & 0.136 \\
$\log \mathrm{IL}-6(\mathrm{pg} / \mathrm{mL})$ & 2.032 & 0.858 to 4.814 & 0.107 \\
\hline
\end{tabular}

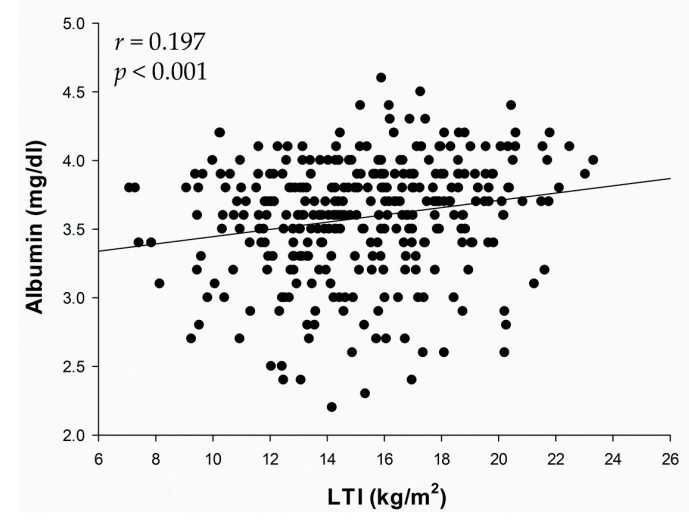

(A)

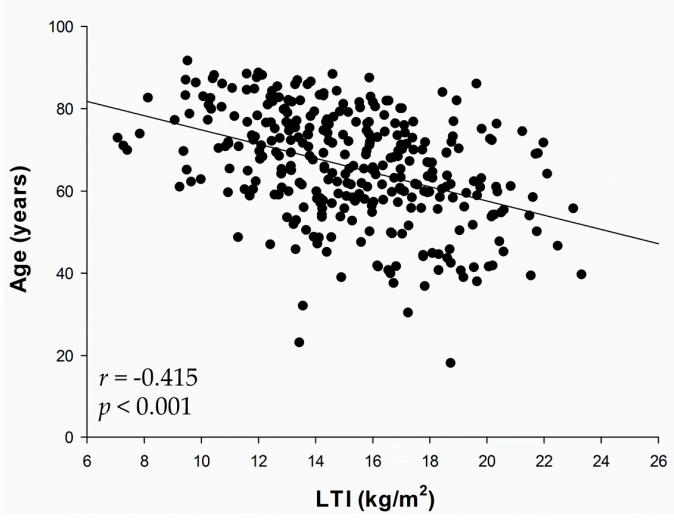

(C)

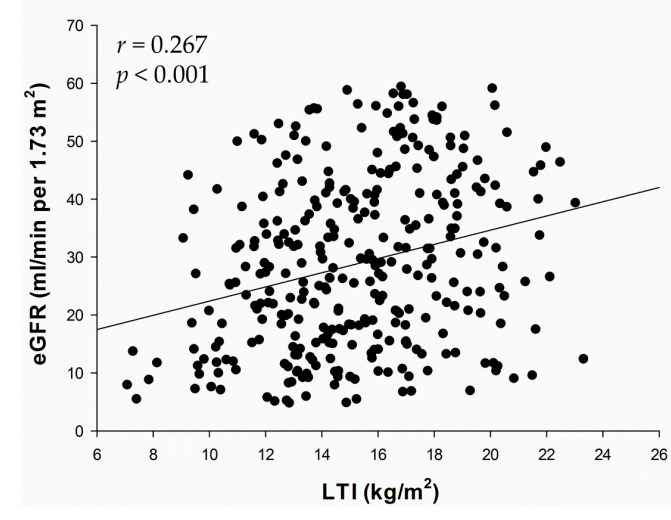

(B)

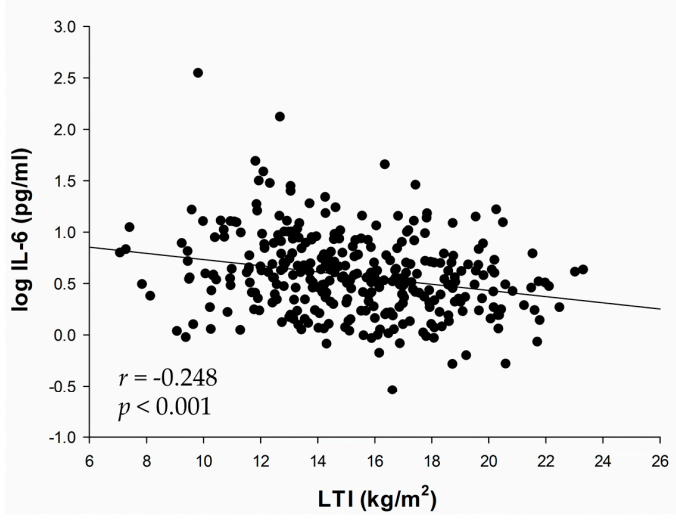

(D)

Figure 1. Univariate analysis of the correlations between LTI and serum albumin (A); eGFR (B); age (C); and $\log$ IL-6 (D). Abbreviations: eGFR, estimated glomerular filtration rate; IL-6, interleukin-6; LTI, lean tissue index.

\section{Discussion}

We found that LTI was independently associated with age, sex, CVD, and IL-6. In addition, we observed that DM was an independent predictor of muscle wasting, defined as LTI being less than $10 \%$ of the normal value in the multivariate logistic regression model. Therefore, LTI has important clinical correlations and may aid in the clinical assessment of patients with stage 3-5 CKD.

Several studies have shown that lean mass decreases with age in older adults without CKD [25-27]. Our study showed that LTI was significantly and negatively associated with age, suggesting that 
age-related muscle wasting also occurs in patients with CKD. Age-related muscle loss may be the result of a disproportionate atrophy of type Ila muscle fibers, decreased synthesis of myosin heavy chain proteins, decline of anabolic hormone levels, loss of innervation, cytokine imbalance, and voluntary inactivity [28]. Undernutrition and decreased physical activity can accelerate age-related muscle loss, and the severity and frequency of sarcopenia increase sharply when patients have several co-morbidities, including osteoporosis, DM, endocrine diseases, neurodegenerative disorders, advanced organ failure, and chronic inflammatory states [3]. Lower LTI values were found in women in our study, consistent with the findings of a previous study that enrolled 14,818 adults using data from the Third National Health and Nutrition Examination Survey (NHANES III) and showed that sarcopenia was greater among older women than among older men [13].

Sarcopenia is common and occurs in all stages of CKD. Foley et al. [29] assessed patients in the NHANES III study and reported a higher prevalence of sarcopenia in patients with lower eGFR. Another cross-sectional study also reported that more advanced stages of CKD are associated with an increased prevalence of sarcopenia [30]. In our study, LTI was positively associated with eGFR, suggesting that preservation of residual renal function may be important to prevent progressive muscle wasting. Protein-energy wasting (PEW) refers to the multiple nutritional and catabolic alterations that occur in CKD [31]. Sarcopenia is a major feature of PEW. The etiology of PEW is multifactorial and involves uremia-induced alterations such as increased energy expenditure, metabolic acidosis, persistent inflammation, and multiple endocrine disorders that result in a state of hypermetabolism leading to excess muscle catabolism [3]. Most of these abnormalities stimulate the ATP-dependent ubiquitin-proteasome system (UPS) pathway, which has been identified as the major pathway in muscle wasting in CKD [32].

We found that DM was an independent predictor for muscle wasting in CKD patients in the present study. Insulin resistance has been identified as one of the most important metabolic challenges in patients with CKD. It is linearly correlated with decline in renal function [33] and is seen in almost all ESRD patients [34]. Furthermore, it is associated with muscle protein degradation, primarily through the UPS pathway. Our results are consistent with previous findings in CKD patients on dialysis. The presence of DM in chronic HD patients is known to increase the risk of protein depletion and the loss of lean body mass [35]. Pupim et al. [36] demonstrated that HD patients with DM had significantly increased muscle protein breakdown compared to non-diabetic HD patients. In a subsequent clinical study [37], it was found that DM is an independent risk factor for muscle wasting in patients with ESRD. Possible mechanisms include concomitant insulin resistance and inflammatory processes. Increased protein loss in the urine and increased energy expenditure in comparison to gender- and age-matched non-diabetic CKD patients further contribute to decreased muscle mass in diabetic CKD patients $[38,39]$.

Low-grade inflammation is common even in earlier stages of CKD, as evidenced by increased circulating levels of inflammatory markers such as C-reactive protein (CRP), IL-6, and TNF- $\alpha$. After multivariate adjustment, IL-6 remained an independent predictor of LTI in our study, suggesting that the development of decreased muscle mass in CKD may be mediated by chronic inflammation. Muscle mass in long-term HD patients is inversely associated with inflammatory markers such as serum IL-6 and CRP levels [40-43]. Several mechanisms for inflammation-induced muscle wasting have been described. For example, TNF- $\alpha$ enhances muscle wasting through the inhibition of myogenic differentiation by activating the nuclear factor-kappa B (NFkB) pathway [44]. Moreover, inflammation contributes to CVD as well as PEW. The concurrence of high IL-6 levels and CVD in patients with decreased LTI in our study corroborates the findings of Stenvinkel et al., who showed a strong association between malnutrition, inflammation, and atherosclerosis (MIA syndrome) in patients with advanced CKD [45].

Some limitations of our study should be acknowledged. Because of the cross-sectional design of the study, causality cannot be established, and there remain some potential unknown or unmeasured confounding factors associated with LTI. Dietary intake was not assessed in this study. Decreased 
protein intake may be a risk factor for loss of lean mass in patients with CKD and should be studied further. The strengths of this study are that the BCM device is portable and relatively inexpensive, and that measurements are non-invasive, simple, rapid, and highly reproducible [46]. Moreover, the BCM can distinguish muscle mass from pathologic fluid retention in $\mathrm{CKD}$, and provide a more accurate estimate of body composition. Another strength is that we were able to identify associating factors for LTI that have not previously been reported in non-dialysis CKD patients.

\section{Conclusions}

A better understanding of the factors associated with decreased muscle mass is needed to develop preventive strategies for muscle wasting in patients with CKD. Muscle mass, as measured by the BCM and expressed as the LTI, is strongly associated with age, sex, DM, CVD, and IL-6. The BCM may help to identify a high-risk group with decreased muscle mass among patients with stage 3-5 CKD. Control of inflammation and underlying comorbidities such as DM and CVD, in addition to appropriate nutritional, pharmalogical, and exercise interventions [47,48], may have protective effects on muscle mass and benefit CKD patients with muscle wasting. Nevertheless, further studies are warranted to confirm our findings.

Acknowledgments: This work was supported by grants from the Research Projects sponsored by the Ministry of Science and Technology, Taiwan (MOST 103-2314-B-005-MY2 and MOST 105-2314-B-014-MY3) and Taipei Tzu Chi Hospital (TCRD-TPE-103-RT-4 and TCRD-TPE-104-RT-4).

Author Contributions: S.C.H. and C.H.P. conceived and designed the experiments; J.L.H. performed the experiments; Y.W.W., T.Y.L. and S.C.H. analyzed the data; Y.W.W. and T.Y.L. wrote the paper.

Conflicts of Interest: The authors declare no conflict of interest.

\section{References}

1. Workeneh, B.T.; Mitch, W.E. Review of muscle wasting associated with chronic kidney disease. Am. J. Clin. Nutr. 2010, 91, 1128S-1132S. [CrossRef] [PubMed]

2. Qureshi, A.R.; Alvestrand, A.; Danielsson, A.; Divino-Filho, J.C.; Gutierrez, A.; Lindholm, B.; Bergstrom, J. Factors predicting malnutrition in hemodialysis patients: A cross-sectional study. Kidney Int. 1998, 53, 773-782. [CrossRef] [PubMed]

3. Cruz-Jentoft, A.J.; Baeyens, J.P.; Bauer, J.M.; Boirie, Y.; Cederholm, T.; Landi, F.; Martin, F.C.; Michel, J.P.; Rolland, Y.; Schneider, S.M.; et al. Sarcopenia: European consensus on definition and diagnosis: Report of the European working group on sarcopenia in older people. Age Ageing 2010, 39, 412-423. [CrossRef] [PubMed]

4. Kim, J.K.; Choi, S.R.; Choi, M.J.; Kim, S.G.; Lee, Y.K.; Noh, J.W.; Kim, H.J.; Song, Y.R. Prevalence of and factors associated with sarcopenia in elderly patients with end-stage renal disease. Clin. Nutr. 2014, 33, 64-68. [CrossRef] [PubMed]

5. Rosenberger, J.; Kissova, V.; Majernikova, M.; Straussova, Z.; Boldizsar, J. Body composition monitor assessing malnutrition in the hemodialysis population independently predicts mortality. J. Ren. Nutr. 2014, 24, 172-176. [CrossRef] [PubMed]

6. Kang, S.H.; Park, J.W.; Yoon, K.W.; Do, J.Y. Limb/trunk lean mass ratio as a risk factor for mortality in peritoneal dialysis patients. J. Ren. Nutr. 2013, 23, 315-323. [CrossRef] [PubMed]

7. Isoyama, N.; Qureshi, A.R.; Avesani, C.M.; Lindholm, B.; Barany, P.; Heimburger, O.; Cederholm, T.; Stenvinkel, P.; Carrero, J.J. Comparative associations of muscle mass and muscle strength with mortality in dialysis patients. Clin. J. Am. Soc. Nephrol. 2014, 9, 1720-1728. [CrossRef] [PubMed]

8. Cheema, B.; Abas, H.; Smith, B.; O’Sullivan, A.J.; Chan, M.; Patwardhan, A.; Kelly, J.; Gillin, A.; Pang, G.; Lloyd, B.; et al. Investigation of skeletal muscle quantity and quality in end-stage renal disease. Nephrology (Carlton) 2010, 15, 454-463. [CrossRef] [PubMed]

9. Goodpaster, B.H.; Park, S.W.; Harris, T.B.; Kritchevsky, S.B.; Nevitt, M.; Schwartz, A.V.; Simonsick, E.M.; Tylavsky, F.A.; Visser, M.; Newman, A.B. The loss of skeletal muscle strength, mass, and quality in older adults: The health, aging and body composition study. J. Gerontol. A Biol. Sci. Med. Sci. 2006, 61, 1059-1064. [CrossRef] [PubMed] 
10. Domanski, M.; Ciechanowski, K. Sarcopenia: A major challenge in elderly patients with end-stage renal disease. J. Aging Res. 2012, 2012, 754739. [CrossRef] [PubMed]

11. Ohkawa, S.; Odamaki, M.; Ikegaya, N.; Hibi, I.; Miyaji, K.; Kumagai, H. Association of age with muscle mass, fat mass and fat distribution in non-diabetic haemodialysis patients. Nephrol. Dial. Transplant. 2005, 20, 945-951. [CrossRef] [PubMed]

12. Hars, M.; Biver, E.; Chevalley, T.; Herrmann, F.; Rizzoli, R.; Ferrari, S.; Trombetti, A. Low lean mass predicts incident fractures independently from frax: A prospective cohort study of recent retirees. J. Bone Miner. Res. 2016, 31, 2048-2056. [CrossRef] [PubMed]

13. Janssen, I.; Heymsfield, S.B.; Ross, R. Low relative skeletal muscle mass (sarcopenia) in older persons is associated with functional impairment and physical disability. J. Am. Geriatr. Soc. 2002, 50, 889-896. [CrossRef] [PubMed]

14. Melton, L.J., 3rd; Khosla, S.; Crowson, C.S.; O'Connor, M.K.; O’Fallon, W.M.; Riggs, B.L. Epidemiology of sarcopenia. J. Am. Geriatr. Soc. 2000, 48, 625-630. [PubMed]

15. Janssen, I.; Shepard, D.S.; Katzmarzyk, P.T.; Roubenoff, R. The healthcare costs of sarcopenia in the United States. J. Am. Geriatr. Soc. 2004, 52, 80-85. [CrossRef] [PubMed]

16. Metter, E.J.; Talbot, L.A.; Schrager, M.; Conwit, R. Skeletal muscle strength as a predictor of all-cause mortality in healthy men. J. Gerontol. A Biol. Sci. Med. Sci. 2002, 57, B359-B365. [CrossRef] [PubMed]

17. Roubenoff, R.; Parise, H.; Payette, H.A.; Abad, L.W.; D'Agostino, R.; Jacques, P.F.; Wilson, P.W.; Dinarello, C.A.; Harris, T.B. Cytokines, insulin-like growth factor 1, sarcopenia, and mortality in very old community-dwelling men and women: The Framingham heart study. Am. J. Med. 2003, 115, 429-435. [CrossRef] [PubMed]

18. Fahal, I.H. Uraemic sarcopenia: Aetiology and implications. Nephrol. Dial. Transplant. 2014, 29, $1655-1665$. [CrossRef] [PubMed]

19. Wabel, P.; Chamney, P.; Moissl, U.; Jirka, T. Importance of whole-body bioimpedance spectroscopy for the management of fluid balance. Blood Purif. 2009, 27, 75-80. [CrossRef] [PubMed]

20. Moissl, U.M.; Wabel, P.; Chamney, P.W.; Bosaeus, I.; Levin, N.W.; Bosy-Westphal, A.; Korth, O.; Muller, M.J.; Ellegard, L.; Malmros, V.; et al. Body fluid volume determination via body composition spectroscopy in health and disease. Physiol. Meas. 2006, 27, 921-933. [CrossRef] [PubMed]

21. Devolder, I.; Verleysen, A.; Vijt, D.; Vanholder, R.; Van Biesen, W. Body composition, hydration, and related parameters in hemodialysis versus peritoneal dialysis patients. Perit. Dial. Int. 2010, 30, 208-214. [CrossRef] [PubMed]

22. Hung, S.C.; Kuo, K.L.; Peng, C.H.; Wu, C.H.; Lien, Y.C.; Wang, Y.C.; Tarng, D.C. Volume overload correlates with cardiovascular risk factors in patients with chronic kidney disease. Kidney Int. 2014, 85, 703-709. [CrossRef] [PubMed]

23. Tsai, Y.C.; Tsai, J.C.; Chen, S.C.; Chiu, Y.W.; Hwang, S.J.; Hung, C.C.; Chen, T.H.; Kuo, M.C.; Chen, H.C. Association of fluid overload with kidney disease progression in advanced CKD: A prospective cohort study. Am. J. Kidney Dis. 2014, 63, 68-75. [CrossRef] [PubMed]

24. Chamney, P.W.; Wabel, P.; Moissl, U.M.; Müller, M.J.; Bosy-Westphal, A.; Korth, O.; Fuller, N.J. A whole-body model to distinguish excess fluid from the hydration of major body tissues. Am. J. Clin. Nutr. 2007, 85, 80-89. [PubMed]

25. Gallagher, D.; Ruts, E.; Visser, M.; Heshka, S.; Baumgartner, R.N.; Wang, J.; Pierson, R.N.; Pi-Sunyer, F.X.; Heymsfield, S.B. Weight stability masks sarcopenia in elderly men and women. Am. J. Physiol. Endocrinol. Metab. 2000, 279, E366-E375. [PubMed]

26. Forbes, G.B.; Reina, J.C. Adult lean body mass declines with age: Some longitudinal observations. Metabolism 1970, 19, 653-663. [CrossRef]

27. Ding, J.; Kritchevsky, S.B.; Newman, A.B.; Taaffe, D.R.; Nicklas, B.J.; Visser, M.; Lee, J.S.; Nevitt, M.; Tylavsky, F.A.; Rubin, S.M.; et al. Effects of birth cohort and age on body composition in a sample of community-based elderly. Am. J. Clin. Nutr. 2007, 85, 405-410. [PubMed]

28. Roubenoff, R. Sarcopenia: Effects on body composition and function. J. Gerontol. A Biol. Sci. Med. Sci. 2003, 58, 1012-1017. [CrossRef] [PubMed]

29. Foley, R.N.; Wang, C.; Ishani, A.; Collins, A.J.; Murray, A.M. Kidney function and sarcopenia in the united states general population: NHANES III. Am. J. Nephrol. 2007, 27, 279-286. [CrossRef] [PubMed] 
30. Moon, S.J.; Kim, T.H.; Yoon, S.Y.; Chung, J.H.; Hwang, H.J. Relationship between stage of chronic kidney disease and sarcopenia in korean aged 40 years and older using the korea national health and nutrition examination surveys (KNHANES IV-2, 3, and V-1, 2), 2008-2011. PLoS ONE 2015, 10, e0130740. [CrossRef] [PubMed]

31. Carrero, J.J.; Stenvinkel, P.; Cuppari, L.; Ikizler, T.A.; Kalantar-Zadeh, K.; Kaysen, G.; Mitch, W.E.; Price, S.R.; Wanner, C.; Wang, A.Y.; et al. Etiology of the protein-energy wasting syndrome in chronic kidney disease: A consensus statement from the international society of renal nutrition and metabolism (IRRNM). J. Ren. Nutr. 2013, 23, 77-90. [CrossRef] [PubMed]

32. Mitch, W.E.; Goldberg, A.L. Mechanisms of muscle wasting. The role of the ubiquitin-proteasome pathway. N. Engl. J. Med. 1996, 335, 1897-1905. [PubMed]

33. Kobayashi, S.; Maesato, K.; Moriya, H.; Ohtake, T.; Ikeda, T. Insulin resistance in patients with chronic kidney disease. Am. J. Kidney Dis. 2005, 45, 275-280. [CrossRef] [PubMed]

34. Mak, R.H.; DeFronzo, R.A. Glucose and insulin metabolism in uremia. Nephron 1992, 61, 377-382. [CrossRef] [PubMed]

35. Cano, N.J.; Roth, H.; Aparicio, M.; Azar, R.; Canaud, B.; Chauveau, P.; Combe, C.; Fouque, D.; Laville, M.; Leverve, X.M.; et al. Malnutrition in hemodialysis diabetic patients: Evaluation and prognostic influence. Kidney Int. 2002, 62, 593-601. [CrossRef] [PubMed]

36. Pupim, L.B.; Flakoll, P.J.; Majchrzak, K.M.; Aftab Guy, D.L.; Stenvinkel, P.; Ikizler, T.A. Increased muscle protein breakdown in chronic hemodialysis patients with type 2 diabetes mellitus. Kidney Int. 2005, 68, 1857-1865. [CrossRef] [PubMed]

37. Pupim, L.B.; Heimburger, O.; Qureshi, A.R.; Ikizler, T.A.; Stenvinkel, P. Accelerated lean body mass loss in incident chronic dialysis patients with diabetes mellitus. Kidney Int. 2005, 68, 2368-2374. [CrossRef] [PubMed]

38. Kaysen, G.A. Diabetes, a cause of progressive sarcopenia in dialysis patients? Kidney Int. 2005, 68, $2396-2397$. [CrossRef] [PubMed]

39. Avesani, C.M.; Cuppari, L.; Silva, A.C.; Sigulem, D.M.; Cendoroglo, M.; Sesso, R.; Draibe, S.A. Resting energy expenditure in pre-dialysis diabetic patients. Nephrol. Dial. Transplant. 2001, 16, 556-565. [CrossRef] [PubMed]

40. Kalantar-Zadeh, K.; Kopple, J.D. Relative contributions of nutrition and inflammation to clinical outcome in dialysis patients. Am. J. Kidney Dis. 2001, 38, 1343-1350. [CrossRef] [PubMed]

41. Stenvinkel, P.; Alvestrand, A. Inflammation in end-stage renal disease: Sources, consequences, and therapy. Semin. Dial. 2002, 15, 329-337. [CrossRef] [PubMed]

42. Guttridge, D.C.; Mayo, M.W.; Madrid, L.V.; Wang, C.Y.; Baldwin, A.S., Jr. NF-kappaB-induced loss of MyoD messenger RNA: Possible role in muscle decay and cachexia. Science 2000, 289, 2363-2366. [CrossRef] [PubMed]

43. Kaizu, Y.; Ohkawa, S.; Odamaki, M.; Ikegaya, N.; Hibi, I.; Miyaji, K.; Kumagai, H. Association between inflammatory mediators and muscle mass in long-term hemodialysis patients. Am. J. Kidney Dis. 2003, 42, 295-302. [CrossRef]

44. Langen, R.C.; Schols, A.M.; Kelders, M.C.; Wouters, E.F.; Janssen-Heininger, Y.M. Inflammatory cytokines inhibit myogenic differentiation through activation of nuclear factor-kappaB. FASEB J. 2001, 15, 1169-1180. [CrossRef] [PubMed]

45. Stenvinkel, P.; Heimbürger, O.; Paultre, F.; Diczfalusy, U.; Wang, T.; Berglund, L.; Jogestrand, T. Strong association between malnutrition, inflammation, and atherosclerosis in chronic renal failure. Kidney Int. 1999, 55, 1899-1911. [CrossRef] [PubMed]

46. Wabel, P.; Chamney, P.; Moissl, U. Reproducibility of bioimpedance spectroscopy for the assessment of body composition and dry weight. J. Am. Soc. Nephrol. 2007, 18, A255.

47. Kalantar-Zadeh, K.; Cano, N.J.; Budde, K.; Chazot, C.; Kovesdy, C.P.; Mak, R.H.; Mehrotra, R.; Raj, D.S.; Sehgal, A.R.; Stenvinkel, P.; et al. Diets and enteral supplements for improving outcomes in chronic kidney disease. Nat. Rev. Nephrol. 2011, 7, 369-384. [CrossRef] [PubMed]

48. Zelle, D.M.; Klaassen, G.; van Adrichem, E.; Bakker, S.J.; Corpeleijn, E.; Navis, G. Physical inactivity: A risk factor and target for intervention in renal care. Nat. Rev. Nephrol. 2017, 13, 152-168. [CrossRef] [PubMed]

(c) 2017 by the authors. Licensee MDPI, Basel, Switzerland. This article is an open access article distributed under the terms and conditions of the Creative Commons Attribution (CC BY) license (http:/ / creativecommons.org/licenses/by/4.0/). 